\title{
Defective viral vectors as agents for gene transfer in the nervous system
}

\author{
Michael G. Kaplitt ${ }^{*}$, Hideo Makimura \\ Division of Neurosurgery, Department of Surgery, New York Hospital-Cornell Medical Center and \\ Laboratory of Biochemical Genetics and Metabolism. The Rockefeller University, New York. NY 1002I. USA
}

\begin{abstract}
Viral vectors have attracted great interest as vehicles for gene therapy. Due to concerns regarding continued viral gene expression in several systems, new approaches have been sought for gene transfer in the nervous system. This article reviews the general concepts and basic biology of defective viral vectors. These are vectors which can package into a viral coat but contain no viral genes, thereby allowing efficient gene transfer in the absence of viral gene expression in target cells. The defective herpes simplex virus (HSV) vector has been applied to numerous interesting questions in neurobiology. The inability to completely eliminate helper viruses has raised concern regarding the application of this vector to human disease. The adeno-associated virus (AAV) vector has recently been introduced into the nervous system. This vector harbors no viral genes, however helper viruses can also be completely eliminated from the system. Although the smaller size may limit the range of applications for this vector, it has received great interest as a potential agent for gene therapy in the nervous system. Potential future directions are discussed as well.
\end{abstract}

Keywords: Defective viral vectors; Gene transfer; Nervous system

\section{Introduction}

Viral vectors have gained widespread use as vehicles for somatic gene transfer into the central nervous system (CNS). The proliferation of publications, meeting presentations and reviews such as those represented in this volume attest to the degree of interest in and acceptance of this technique by the neurobiology community. In order to genetically modify cells of the central nervous system in situ, DNA viruses are used as the basis for currently available vectors. Although several DNA viruses have been modified or exploited in a variety of ways, viral vectors can in general be assigned to one of two major categories: recombinant viral vectors or defective viral vectors. Recombinant vectors have been the most widely used vehicles in neurobiology and have been described in great detail elsewhere in this issue. This group will be discussed briefly below solely for the purposes of definition. Defective viral vectors have received more limited use. However, significant advancements and achievements have been made using these systems. This article will review the basic biology of defective viral vectors and

\footnotetext{
'Corresponding author.
}

certain specific applications will also be presented for illustrative purposes.

Recombinant viral vectors can be viewed as any virus which contains a foreign gene inserted within a variant of the native viral chromosome. Adenovirus (Ad) (Berkner, 1988; Graham and Prevec, 1992; Goff and Shenk, 1993; Kozarsky and Wilson, 1993) and herpes simplex virus (HSV) (Roizman and Jenkins, 1985; Shi et al., 1984) have been the principle DNA viruses used to create recombinant vectors, and they are discussed in detail elsewhere. The term recombinant vectors stems from the fact that the gene of interest is most often inserted within the viral genome by homologous recombination. Since wild-type viruses usually possess some degree of pathogenicity, these viruses are then further modified in order to reduce the virulence. Thus one or more genes essential for viral replication may be removed by homologous recombination in the same manner that the foreign gene is inserted. The foreign gene may even be inserted in place of some gene essential for viral pathogenicity, thereby achieving both goals with a single recombination event. Usually the gene(s) removed are essential for viral replication, which is one of the major causes of virus-associated pathology (Engelhardt et al., 1994; Halbert et al., 1985). Vectors are then produced and grown in tissue culture using cell-lines which constitutively express the missing viral gene product, so that a 
productive infection can occur within these cultured cells but will not occur in vivo (DeLuca et al., 1985; Shenk and Williams, 1984). Still other deletions have been generated which would serve to limit neurovirulence or prevent inflammatory responses to the continued expression of viral gene products within the target cells (Ginsberg et al., 1991; Simon et al., 1993; Zabner et al., 1994). Among practitioners of gene transfer, these vectors have been variously described as reduced virulence, replication-deficient, replication-defective or defective. Since these vectors are generated by insertion or deletion of genes via homologus recombination, for the purposes of the current discussion the term recombinant viral vectors will be used to describe this class of reagents.

\section{Defective viral vectors}

Defective viral vectors represent the other major group of DNA viral vectors. The major difference between these two groups is that defective vectors do not possess any viral genes but contain only recognition signals which permit replication and packaging of any foreign DNA into a viral coat (Spaete and Frenkel, 1982). DNA viruses of all varieties possess signals which permit recognition of the DNA genome by viral proteins in order to initiate replication as well as to permit packaging of the progeny DNA into new viral particles (Frenkel et al., 1980; Vlazny and Frenkel, 1981; Stow and McMonagle, 1982; Spaete and Frenkel, 1985; Deiss et al., 1986). These recognition signals do not encode any viral gene products and therefore they are by definition not genes. These have been called 'cis-acting' signals or elements because, in the presence of viral proteins, they can only allow replication and packaging of the DNA sequences to which they are covalently attached. The necessary viral proteins are then said to function 'in trans' because they can promote replication and packaging of any DNA existing within the same nuclear compartment and which bears the appropriate cisacting elements. The genome of defective viral vectors thus contain only viral cis-acting elements which permit DNA replication and packaging into a viral coat in the presence of the appropriate trans-acting factors.

The term defective viral vectors derives from a variant observed in nature called the defective interfering particle (DIP) (Von Magnus, 1954; Huang, 1973; Frenkel, 1981). Often when viruses replicate mutations occur which serve as part of the basis for natural selection. Certain viruses are highly recombinogenic, however, and therefore at some frequency will generate replicative products which harbor substantial deletions in the viral genome. HSV is an example of such a virus (Frenkel et al., 1976; Locker and Frenkel, 1979; Frenkel et al., 1980; Locker et al., 1982). When grown at a high multiplicity of infection (the infectious virus-to-cell ratio), particles will be generated which contain only a limited subset of the $150 \mathrm{~kb}$ HSV genome
(Frenkel et al., 1976). These particles contain deletions of numerous essential viral genes, and therefore cannot replicate on their own (Frenkel, 1981). Thus they are 'defective' with respect to replication. These deleted genomes retain the necessary cis-acting elements, however, and therefore can package into an HSV coat (Spaete and Frenkel, 1982; Stow and McMonagle, 1982). The missing viral proteins are then provided by wild-type HSV which will co-infect the target cell along with the DIP (Kwong and Frenkel, 1995). Thus the DIP cannot autonomously replicate but absolutely requires co-infection of a cell by this 'helper virus' for propagation. Since DIP can also actively interfere with replication of the helper virus, the term defective interfering particle is used to describe these natural variants (Frenkel et al., 1980; Frenkel, 1981).

Defective viral vectors represent a synthetic variant of this phenomenon. Rather than depend upon nature to generate the necessary vehicle, modern molecular biological techniques have been used to isolate the appropriate viral cis-acting elements and splice them together with any interesting foreign gene. Most frequently this is performed through a plasmid intermediate in order to easily produce and purify large amounts of the defective vector genome (Spaete and Frenkel, 1982). To create a packaged defective viral vector, the plasmid is first introduced into cells in tissue culture by transfection. Viral proteins requisite for replication and packaging, as well as structural proteins for the resulting particle, are then provided in trans by one or more viral genomes (Spaete and Frenkel, 1982; Kwong and Frenkel, 1995). This can be done either by co-transfection of DNA encoding these proteins with the vector plasmid, or by 'superinfecting' transfected cells with an infectious helper virus (Spaete and Frenkel, 1982; Kaplitt et al., 1991; Kwong and Frenkel, 1995). The resulting viral stock will then contain progeny helper vinus mixed with packaged defective viral vectors which contain no viral genes and cannot autonomously replicate. Since the contaminating helper virus represents a continued source of potential toxicity, strategies discussed below have centered upon either using helper viruses of reduced virulence or completely eliminating the helper virus in order to generate a stock of pure defective viral vectors.

\section{Defective IISV vectors}

The first application of defective viral vectors in neurobiology utilized the defective HSV vector. The HSV genome consists of 150 kilobases $(\mathrm{kb})$ of double-stranded DNA which encodes approximately 75 genes (Roizman, 1990; Roizman and Sears, 1990). As indicated above, the defective $\mathrm{HSV}$ vector was originally designed as a result of research into HSV defective interfering particles. When isolated in nature, these particles consisted of multiple copies of a subset of the entire HSV genome packaged into an HSV coat (Spaete and Frenkel, 1982, Spaete and 


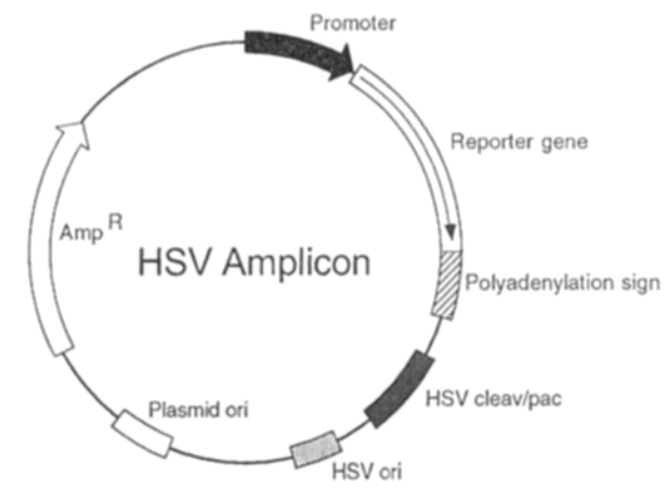

Fig. 1. The HSV amplicon. The HSV amplicon is a plasmid which contains the HSV origin of DNA replication and the HSV cleavage/packaging signal. No viral gene are contined within the plasmid. In the presence of protcins provided by the IISV helper virus, the amplicon will package into an HSV coat.

Frenkel, 1985; Stow and McMonagle, 1982; Vlazny et al., 1982). Since DIPs required co-infection by an HSV helper vinus in order to propagate, it was determined that one or more proteins essential for replication and/or packaging was absent from the fragment of HSV DNA present within the DIP. In order for the fragment to replicate and package, however, it was believed that the requisite cis-acting recognition elements for replication and cleavage/packaging of the DNA into an HSV coat were present in all DIPs (Spaete and Frenkel, 1982, Spaete and Frenkel, 1985; Stow and McMonagle, 1982). After examining the DNA of various DIPs, a common fragment was identified. Insertion of this fragment into a plasmid resulted in replication and packaging of the plasmid DNA into an HSV coat when the plasmid DNA was co-transfected with wild-type HSV DNA in tissue culture (Spaete and Frenkel, 1982, Spaete and Frenkel, 1985; Stow and McMonagle, 1982). Since the entire plasmid was packaged, including any foreign DNA sequences, and the resulting viral particle could transmit the packaged DNA to a new cell, it was recognized that this system represented an attractive new DNA gene transfer vehicle. Further research eventually demonstrated that this fragment contained an HSV origin of DNA replication (termed the HSV ori) (Stow and McMonagle, 1982, Stow and McMonagle, 1983; Stow, 1985; Elias and Lehman, 1988; Challberg, 1991: Olivio et al., 1991) and a signal for cleavage and packaging of viral DNA (termed the HSV a sequence since it resides within the repeated a subunit of the HSV genome) (Vlazny and Frenkel, 1981; Vlazny et al., 1982; Spaete and Frenkel, 1985: Deiss et al., 1986; Deiss and Frenkel, 1986).

The plasmid upon which the defective HSV vector is based was called an amplicon (Fig. 1). In the presence of proteins provided by the HSV helper virus. the amplicon will package into an HSV coat (Fig. 2). Since approxi mately $150 \mathrm{~kb}$ of DNA must be packaged into an HSV particle, then substantially smaller subunits of DNA containing the requisite ori and cleavage/packaging sequences will be replicated in tandem repeats prior to packaging (Kwong and Frenkel, 1995). Thus if a $10 \mathrm{~kb}$ amplicon is used as the genome, roughly 15 copies of this plasmid will be packaged into a single HSV particle. This will result in delivery of 15 copies of the foreign gene of interest to a cell for each individual defective HSV vector particle, thereby 'amplifying' gene delivery. Since the amplicon also contains HSV cis-acting elements without any HSV genes, only the gene product of interest will be expressed in the absence of any HSV gene expression. This became an attractive gene transfer vehicle, particularly for the CNS. since much of the basis for pathogenicity due to direct cytotoxic effects of immune reactions to HSV gene products would be limited.

While these features of the defective HSV vector are attractive, the inability to completely elminate the helper

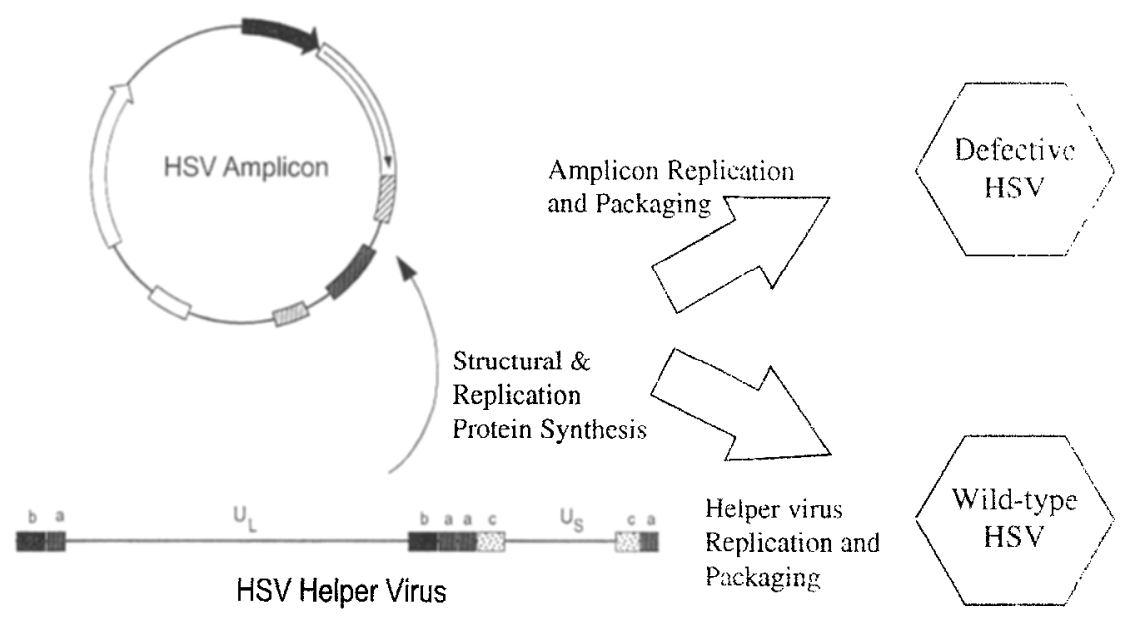

Fig. 2. Generation of the defective HSV Vector. The amplicon is first transfected into cells. HSV genome is introduced either by co-transfection or 'superinfection' the following day. Only the helper virus will express the viral genes which will allow replication and packaging of both the amplicon and the HSV genome. The resulting stock consists of both defective vectors and progeny helper virus. A deletion or temperature-sensitive mutant helper virus is usually employed in order to limit toxicity. Since the two particles are virtually identical in size and surface proteins, it is not possible to physically separate the two particles. 
virus to date has severely limited the potential advantages of this system. In order to generate the packaged vector, HSV proteins must be provided in trans by either co-transfection of HSV DNA or 'superinfection' with HSV after transfection of the amplicon into cultured cells (Kwong and Frenkel, 1995). The resulting stock then consists of a mix of defective HSV vectors and progeny helper HSV. Initially a stock may contain mostly helper virus, but the amplicon is capable of interfering with helper virus replication. Thus, with subsequent passaging, the ratio of defective to helper virus changes, and by $4-8$ passages a stock consisting of greater than $90 \%$ defective vectors can be generated (Kwong and Frenkel, 1995). This serves to substantially limit potential problems due to residual helper virus, however clearly toxicity from the helper virus is not entirely eliminated in this system. Physical separation of the two particles is impossible, since the only difference between these two species is the base composition of the DNA. Initially wild-type HSV was used as a helper vinus, but even a small number of residual particles can rapidly replicate and spread following CNS injection, resulting in substantial toxicity and death. In order to use the defective HSV vector as a CNS gene transfer vehicle, mutant helper viruses were used (Geller and Breakefield, 1988; Geller et al., 1990; Kaplitt et al., 1991). These mutants allow generation of defective vectors in tissue culture under permissive conditions, however the mutations render the helper viruses inactive in vivo (Deluca et al., 1985; Paterson and Everett, 1990).

The defective HSV vector has been used for a widerange of in vivo gene transfer studies. After the initial demonstration that the vector could result in successful gene transfer to non-dividing neurons and glial cells in vitro and in vivo (Geller and Breakefield, 1988; Kaplitt et al., 1991), a variety of functional studies demonstrated the flexibility of this system. Expression of the NGF receptor has resulted in functional recovery of peripheral nerves following axotomy (Federoff et al., 1992; Xu et al., 1994), while expression of both bcl-2 and the glucose transporter have both provided protection from possible ischemic insults in the brain (Ho et al., 1993; Federoff, 1995). Transfer of the gene for tyrosine hydroxylase into the striatum of animals with unilateral lesions of the substantia nigra has resulted in significant behavioral improvement (Geller et al., 1995). The defective HSV vector has also been used as an alternative to transgenic mice for in vivo promoter analysis, with important regions of the rat preproenkephalin promoter identified through in vivo deletion analysis (Kaplitt et al., 1994b; Yin et al., 1995). Finally, insertion of two transcription units into a single vector has resulted in synthesis of two foreign gene products within a single cell (Verhaagen et al., 1995). These represent only a few examples of the numerous successes that have been achieved using the defective HSV vector. The inability to eliminate contaminating helper virus, with the resulting expression of HSV proteins from even mutant helper viruses in target tissues, led to the search for other defective viral vectors which may permit complete elimination of helper virus.

\section{AAV vectors}

Adeno-associated virus (AAV) is a naturally occurring defective virus. AAV is a $4.7 \mathrm{~kb}$ single-stranded DNA virus (Strivastava et al., 1983) which is usually found in tissues which are also infected by adenovirus, which is the derivation for the name of the virus. Productive AAV infection requires coinfection by adenovirus (Atchison et al., 1965; Melnick et al., 1965; Hoggan et al., 1966) or HSV (Buller et al., 1981; McPherson et al., 1985), which may serve as helper viruses for both wild-type AAV and for the vector described below. Although the precise role of all helper functions has not been fully determined, adenovirus proteins have been shown to be important for transactivating AAV promoters (Richardson and Westphal, 1981, Richardson and Westphal, 1984; Tratschin et al., 1985; Chang et al., 1989; Flint and Shenk, 1989), stabilizing AAV mRNA and enhancing the efficiency of translation of some AAV mRNAs (Strauss et al., 1976; Jay et al., 1979; Myers et al., 1980; Richardson and Westphal, 1981; Jay et al., 1981; McPherson et al., 1982; West et al., 1987; Janik et al., 1989). In the absence of helper virus, the wild-type virus will enter into a latent state from which the AAV genome may later be 'rescued' (Hoggan et al., 1972; Berns et al., 1975; Handa et al., 1977; Cheung et al., 1980). Wild-type AAV can also integrate into a specific site in human chromosome 19 when entering the latent state (Kotin et al., 1990; Samulski et al., 1991), which is unique among DNA viruses. Unlike HSV defective interfering particles, however, AAV is a distinct virus which is much smaller than the helper adenovirus $(35 \mathrm{~kb})$ or HSV $(150 \mathrm{~kb})$ and which possesses a unique capsid consisting of AAV-specific structural proteins encoded by the AAV genome (Johnson et al., 1971, Johnson et al., 1975; Rose et al., 1971; Tsao et al., 1991).

AAV was an attractive candidate as a vector for gene therapy since wild-type AAV is already defective and has not been associated with any human disease (Berns et al., 1982). Since the AAV chromosome is small (less than 5 $\mathrm{kb})$, the entire genome can easily be cloned into a plasmid. As a DNA virus, $\Lambda \mathrm{AV}$ possesses cis-acting signals for replication and packaging, however these reside within the 125 bp terminal repeats flanking the rest of the AAV genome (Samulski et al., 1987, Samulski et al., 1989; McLaughlin et al., 1988). When flanked by the AAV terminal repeats, foreign DNA could be packaged into an AAV coat when transfected cells were infected with wildtype AAV and helper adenovirus (Hermonat and Muzyczka, 1984; Tratschin et al., 1985; Samulski et al., 1987, Samulski et al., 1989; McLaughlin et al., 1988). This provided the basis for the AAV vector. As with the 


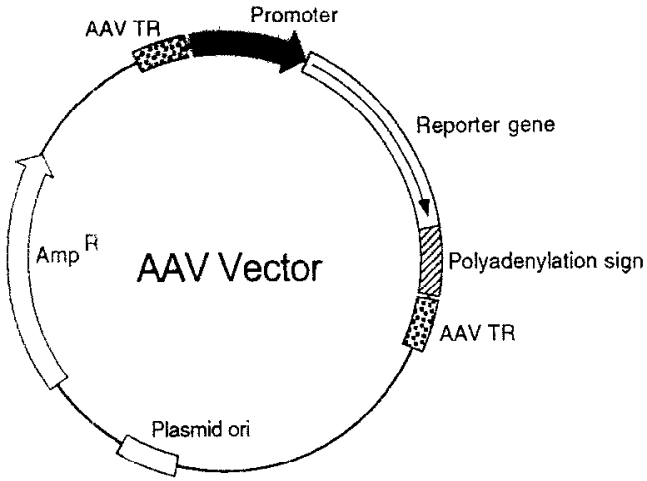

Fig. 3. The AAV Vector. The AAV vector plasmid consists of two AAV terminal repeats which contain the necessary origin of DNA replication and packaging signals. No AAV genes are present within the plasmid. In the presence of AAV replication and structural proteins, the sequences between the terminal repeats will be packaged into an AAV coat.

defective HSV vector, however, residual contamination by wild-type AAV and helper adenovirus represented a continued difficulty. Thus a novel system was developed for creation of a DNA viral vector which is completely free of contaminating helper virus.

The AAV vector as currently practiced is based upon a two plasmid system (Samulski et al., 1989). The vector, as described above, contains foreign sequences of interest up to $5 \mathrm{~kb}$ flanked by the $125 \mathrm{bp}$ AAV terminal repeats (Fig. 3 ). When oriented properly the DNA between the repeats will be packaged into an AAV coat. A second plasmid is then used called the 'helper plasmid'. This consists of the entire AAV genome without the terminal repeats (Fig. 4). The heiper plasmid can thus express all of the AAV proteins necessary for replication, packaging and creation of new particles, however the absence of terminal repeats prevents the helper plasmid from packaging. Co-transfection of these two plasmids will thus result in replication and packaging of the vector into an AAV particle, while the AAV genes in the helper plasmid will not be packaged and will thus be lost (Fig. 4). Finally, infection by adenovirus is still necessary for this process to efficiently occur (Samulski et al., 1989). Thus the resulting vector stock consists of defective AAV vectors with no AAV genes, and progeny helper adenovirus (Fig. 4), Unlike the defective HSV vector, however, the contaminating helper virus in this instance is completely distinct from the vector (Samulski et al., 1987; Samulski et al., 1989). For example, the stock is first heated to $56^{\circ} \mathrm{C}$ for $30-45 \mathrm{~min}$, which will inactivate the adenovirus while leaving the AAV intact. Then cesium chloride centrifugation permits physical separation of the inactivated adenovirus from the AAV vector due to the vastly different particle sizes. Following dialysis to remove the cesium chloride, a stock of helperfree defective AAV vectors is obtained (Bartlett and Samulski, 1995). Thus AAV represents the first DNA viral vector which contains no viral genes and is not contaminated by helper virus, thereby eliminating pathogenicity due to toxicity or immunogenicity of viral gene products.

The AAV vector has only recently been applied to neurobiology. While relatively new to the field of gene

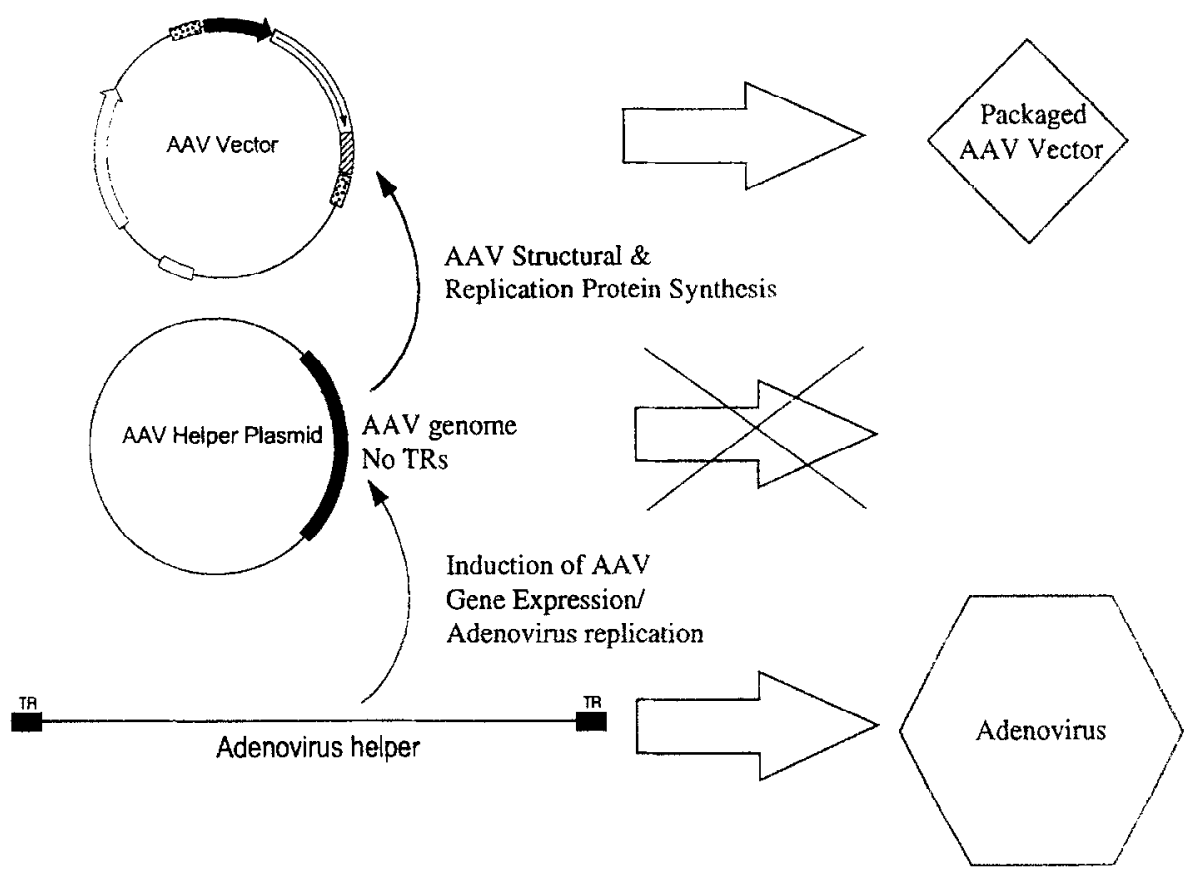

Fig. 4. Generation of AAV Vectors. The AAV vector is transfected into cells. At the same time a second plasmid is transfected, called the helper plasmid. The helper plasmid contain all of the AAV coding regions but lacks terminal repeats. Thus the helper plasmid can support AAV replication and packaging but cannot itself replicate and package. Finally, adenovins infection is required for efficient expression of the AAV genes from the hetper plasmid. The resulting stock consists of the fully defective AAV vector and progeny helper virus, but no wild-type AAV is present. The adenovirus can then be removed from the stock resulting in a pure population of defective AAV vectors. 
therapy in general, AAV vectors have been used for several applications outside of the CNS. For example, AAV vectors have been shown to efficiently transduce bone marrow progenitor cells for the purpose of either correcting hematologic disorders with a genetic basis or to provide proteins to the body via blood cells (Zhou et al., 1993; Goodman et al., 1994; Miller et al., 1994). Since AAV can infect airway epithelium in a manner analagous to adenovirus, AAV vectors have generated interest as agents for transfer of the CFTR gene in order to treat cystic fibrosis (Flott et al., 1993). More recently, AAV vectors have been used for gene transfer into the CNS in vivo (During et al., 1994a; Kaplitt et al., 1994a). While some transduction of glial cells was demonstrated, the vast majority of modified cells appeared to be neuronal (Kaplitt et al., 1994a). Further examination of this phenomenon has suggested that there may be regional influences upon both the efficiency and cell-specificity of AAV-mediated transduction in vivo. Finally, long-term therapeutic improvement in the rat 6-hydroxydopamine model of Parkinsonism following tyrosine hyroxylase gene transfer into the striatum suggests that AAV vectors may be useful as potential agents for safe and efficient gene therapy of CNS disorders (Kaplitt et al., 1994a).

\section{Future directions}

This review has been intended to outline the current state of the art with respect to defective viral vectors as gene transfer agents, particularly for study and possible treatment of the central nervous system. Certain applications have also been presented, although an exhaustive review of all applications to date was not intended. Gene therapy is a rapidly evolving field, however, and the number of researchers using these techniques as well as the variety of applications is exponentially expanding. Currently no single gene transfer vehicle is ideal, and numerous laboratories are investigating issues common to all gene transfer stratcgies such as creating synthetic, cell-specific promoters or modification of viral surface proteins. Since defective viral vectors represent important agents for safe and efficient gene transfer, however, rapid advances in the current technology will doubtless be achieved. For example, promising data suggesting the possibility of a helper-free defective HSV vector has already been generated. Furthermore, since the requisite cis-acting elements for most DNA vinuses have been identified, it will be relatively simple to generate defective vectors based upon other DNA viruses. Many of these systems will be quite inefficient at either creating vectors or transferring genes to target cells. Thus future work will concentrate upon applying the appropriate vector to the question at hand and then maximizing the efficiency of that system for the given purpose. As is evident from this review, however, the desire for optimized systems should not deter those interested in using defective viral vectors at present, since the current state of the art permits numerous novel approaches to the study of the central nervous system.

\section{References}

Atchison, R.W., Casto, B.C. et al. (1965) Adenovirus-associated defective virus particles, Science, 149: 754-756.

Bartlett, J.S. and Samulski, R.J. (1995) Genetics and biology of adeno-associated virus. In M.G. Kaplitt and A.D. Loewy (Eds.), Viral Vectors, Academic Press, San Diego, CA, pp. 56-76.

Berkner, K.L. (1988) Development of adenovirus vectors for the expression of heterologous genes, Biotechniques, 6: 616-629.

Berns, K.I., Cheung, A., Ostove, J.M. and Lewis, M. (1982) Adeno-associated virus latent infection. In B.W.J. Mahy, A.C. Minson et al. (Eds.), Virus Persistence, Cambridge University Press, Cambridge, p. 249.

Berns, K.I., Pinkerton, T.C. et al. (1975) Detection of adeno-associated virus (AVV) specific nucleotide sequences in DNA isolated from latently infected Detroit 6 cells, Virology, 68: 556-560.

Buller, R.M., Janik, J.E., Sebring, E.D. and Rose, J.A. (1981) Herpes simplex virus types 1 and 2 completely help adenovirus-associated virus replication, J. Virol., 40: 241-247.

Challberg, M.D. (1991) Herpes simplex vinus DNA replication, Semin. Virol., 2: 247-256.

Chang, L.-S., Shi, Y. and Shenk, T. (1989) Adeno-associated virus p5 promoter contains an adenovirus EIA inducible element and a binding site for the major large transcription factor, J. Virol., 63: 3479-3488.

Cheung, A.K., Hoggan, M.D. et al. (1980) Integration of the adeno-associated virus genome into cellular DNA in latently infected human Detroit 6 cells, J. Virol., 33: 739-748.

Deiss, L.P., Chou, J. and Frenkel, N. (1986) Functional domains within the a sequence involved in the cleavage/packaging of herpes simplex virus DNA, J. Virol., 59: 605-618.

Deiss, L.P. and Frenkel, N. (1986) The herpes simplex virus amplicon: cleavage of concatemeric DNA is linked to packaging and involves amplification of the terminally reiterated a sequence, J. Virol., 57: 933-941.

DeLuca, N.A., McCarthy, A.M. and Schaffer, P.A. (1985) Isolation and characterization of deletion mutants of herpes simplex vinus type 1 in the gene encoding immediate early regulatory protein ICP4, J. Virol., 56: $558-570$.

During, M.J., Naegele, J.R., O'Malley, K.L. and Geller, A.I. (1994a) Long-term behavioral recovery in Parkinsonian rats by an HSV vector expressing tyrosine hydroxylase, Science, 266: 1399-1403.

Elias, P. and Lehman, I.R. (1988) Interaction of origin binding protein with an origin of replication of HSV type 1, Proc. Natl. Acad. Sci USA, 85, 2959-2963.

Engelhardt, J.F., Ye, X., Doranx, B. and Wilson, J.M. (1994) Ablation of E2A in recombinant adenovinus improves transgene persistence and decreases inflammatory response in mouse liver, Proc. Natl. Acad. Sci. USA, 91: 6196-6200.

Federoff, H.J., Geschwind, M.D., Geller, A.I. and Kessler, J.A. (1992) Expression of nerve growth factor in vivo, from a defective HSVI vector prevents effects of axotomy on sympathetic ganglia, Proc. Natl. Acad. Sci. USA, 89: 1636-1640.

Federoff, H.J. (1995) The use of defective herpes simplex virus amplicon vectors to modify neural cells and the nervous system. In: M.G. Kaplitt and A.D. Loew (Eds.), Viral Vectors, pp. 109-118.

Flint, J. and Shenk, T. (1989) Adenovirus EIA protein paradigm viral transactivator, Annu. Rev. Genet., 23: 141-161.

Flott, T.R., Afione, S.A., Conrad, C., McGrath, S.A., Solow, R., Oka, H, Zeitlies, P.L., Guggino, W.B. and Carter, B.J. (1993) Stable in vivo expression of the cystic fibrosis transmembrane conductance regulator 
with adeno-associated virus, Proc. Natl. Acad. Sci. USA, 90: 1061310617.

Frenkel. N. (Ed.) (1981) Defective interfering herpes vinus. In: The Human Herpes Virus - An Interdisciplinary Prospective. ElsevierNorth Holland, New York.

Frenkel, N., Locker, H., Batterson, B., Hayward, G.S. and Roizman, B. (1976) Anatomy of herpes simplex virus VI. Defective DNA originates from the S component, J. Virol., 20: 527-531.

Frenkel, N., Locker, H. and Vlazny, D.A. (1980) Studies of defective herpes simplex vinuses, Ann. NY Acad. Sci., 354: 347-370.

Geller, A.I, and Breakefield, X.O. (1988) A defective HSV 1 vector expresses $E$. coli beta-galactosidase in cultured peripheral neurons, Science, 241: 1667-1669.

Geller, A.I., During, M.J., Oh, Y.J., Freese, A. and O'Malley, K.L. (1995) An HSV 1 vector expressing tyrosine hydroxylase causes production and release of L-dopa from cultured rat striatal cells, J. Neurochem., 64: 487-496.

Geller, A.I., Keyomarsi, K., Bryan, J. and Pardee, A.B. (1990) An efficient deletion mutant packaging system for defective herpes simplex vectors: potential applications to human gene therapy and neuronal physiology, Proc. Natl. Acad. Sci. USA, 87: 8950-8954.

Ginsberg, H.S., Moldawer, L.L., Sehgal, P.B., Redington, M., Kilian, P.L., Chanok, R.M. and Prince, G.A. (1991) A mouse model for investigating the molecular pathogenesis of adenovirus pneumonia, Proc. Natl. Acad. Sci. USA, 88: 1651-1655.

Goff, S.P. and Shenk, T. (1993) Sleeping with the enemy: viruses as gene transfer agents, Curr. Opin. Genet. Dev., 3: 71-73.

Goodman, S., Xiao, X., Donahue, R.E., Moulton, A., Miller, J., Walsh, C., Young, N.S., Samulski, R.J. and Nienhuis, A.W. (1994) Recombinant adeno-associated virus-mediated gene transfer into hematopoietic progenitor cells, Blood, $84(5): 1492-1500$.

Graham, F.L. and Prevec, L. (1992) In R.W. Ellis (Ed.), Vaccines: New Approaches to Immunological Problems. Butterworth-Heinemann, Boston, pp. 363-390.

Halbert, D.N., Cutt, J.R. and Shenk. T. (1985) Adenovirus early region 4 encodes functions required for efficient DNA replication, late gene expression and host cell shutoff, J. Virol., 56: 250-257.

Handa, H., Hiroki, K. et al. (1977) Establishment and characterization of KB cell lines latently infected with adeno-associated virus type 1 , Virology, 82: 84-92.

Ho, D., Mocarski, E. and Sapolski, R. (1993) Altering central nervous system physiology with a defective herpes simplex virus vector expressing the glucose transporter gene, Proc. Natl. Acad. Sci. USA. 90: $3655-3659$.

Hoggan, M.D., Blacklow, N.R. and F.B. Rowe (1966) Studies of small DNA viruses found in various adenovirus preparations: physical biological and immunological characteristics, Proc. Natl. Acad. Sci. USA, 55: 1457-1471.

Hoggan, M.D., Thomas, G.F. and Johnson, F.B. (1972) Continuous carriage of adenovirus associated virus genome in cell culture in the absence of helper adenovirus. In Proceedings of the Fourth Lepetite Colloquium, Cocoyac, Mexico.

Hermonat, P.L. and Muzyczka, N. (1984) Use of adeno-associated virus as a mammalian DNA cloning vector: transduction of neomycin resistance into mammalian tissue culture cells, Proc. Natl. Acad. Sci. USA, $81: 6466-6470$.

Huang, A.S. (1973) Defective interfering viruses, Annu. Rev. Microbiol., $27: 101-117$.

Janik, J.E., Huston, M.M., Cho, K. and Rose, J.A. (1989) Efficient synthesis of adeno-associated virus structural proteins requires both adenovirus DNA binding protein and VA I RNA, Virology, 168 : 320-329.

Jay, F.T., De La Maza, L.M. and Carter, B.J. (1979) Parvovirus RNA transcripts containing sequences not present in mature mRNA: a method for isolation of putative mRNA precursor sequences, Proc. Natl. Acad. Sci. USA, 76: 625-629.
Jay, F.T., Laughlin, C.A. and Carter, B.J. (1981) Eukaryotic translationa] control: adeno-associated virus protein synthesis is arrested by a mutation in the adenovirus DNA binding protein, Proc. Natl. Acad. Sci. USA, 78: 2927-2931.

Johnson, F.B., Ozer, H.L. and Hoggan, M.D. (1971) Structural proteins of adenovirus-associated virus type 3, J. Virol., 8: 860-863.

Johnson, F.B., Whitaker, C.W. and Hoggan, M.D. (1975). Structural polypeptides of adenovirus associated virus top component. Virology. 65: $196-203$.

Kaplitt, M.G., Pfaus, J.G., Kleopoulas, S.P., Houlon, B.A., Rabkin, S.O. and Pfaff, D.W. (1991) Expression of a functional foreign gene in adult mammalian brain following in vivo transfer via a herpes simplex vinus defective viral vector, Mol. Cell. Neurosci., 2: 320-3.30.

Kaplitt, M.G., Leone, P., Samuiski, R.J., Xiao, X., Pfaff, D.W., O'Malley, K.L. and During, M.J. (1994a) Long-term gene expression and phenotypic correction using adeno-associated virus vectors in the mammalian brain, Nature Genet., 8: 148-153.

Kaplitt, M.G., Kwong, A.D., Kleopoulos, S.P., Mobbs, C.V., Rabkin, S.D. and Pfaff, D.W. (1994b) Preproenkephalin promoter yields region-specific and long-term expression in adult brain after direct in vivo gene transfer via a defective herpes simplex viral vector, Proc. Natl. Acad. Sci. USA, 91: 8979-8983.

Kotin, R.M., Sinisalco, M., Samulskio, R.J., Zlu, X.D., Huuter, L. and Laughlin, C.A. (1990) Site-specific integration by adeno-associated virus, Proc. Natl. Acad. Sci. USA, 87: 2211-2215.

Kozarsky, K. and Wilson, J.M. (1993) Gene therapy: adenovinus vectors. Curr. Opin. Genet. Dev., 3: 499-503.

Kwong, A.D. and Frenkel, N. (1995) Biology of herpes simplex virus (HSV) defective viruses and development of the Amplicon system. In M.G. Kaplitt and A.D. Loewy (Eds.) Viral Vectors, Academic Press, San Diego, CA, pp. 25-42.

Locker, H. and Frenkel, N. (1979) Structure and origin of defective genomes contained in serially passaged herpes simplex virus type 1 (Justin), J. Virol., 29; 1065-1077.

Locker, H., Frenkel. N. and Halliburton. I. (1982) Structure and expression of class II defective herpes simplex virus genomes encoding infected cell polypeptide number 8, J. Virol., 43: 574-593.

McLaughlin, S.K.. Collis, P. and Hermonat, P.L. (1988) Adeno-associated virus general transduction vectors: analysis of proviral structures, I. Virol., 62: 1963-1973.

McPherson, R.A., Ginsburg, H.S. and Rose, J.A. (1982) Adeno-associated virus helper activity of adenovinus DNA binding protein, J. Virol, 44: 666-673.

McPherson, R.A., Rosenthal, L.J. and Rose, J.A. (1985) Human cytomegalovirus completely helps adeno-associated vins replication, Virology, 147: 217-222.

Melnick, J.L., Mayor, H.D., Smith, K.O. and Rapp, F. (1965) Association of 20 millimicron particles with adenoviruses. J. Bacteriol., 90 : $27 \mathrm{i}-274$.

Miller, J.L., Donahue, R.E,, Seller, S.E., Sanutski, R.J., Yonne, N.S, and Nienhuis, A.W. (1994) Recombinant adeno-associated vinus (rAAV) mediated expression of a human $\gamma$-globin gene in human progenitor derived erythyroid cells, Proc. Natl. Acad. Sci. USA, 91: 10183.. 10187.

Myers, M.W., Laughlin. C.A., Jay, F.T. and Carter, B.J. (1980) Adenovirus helper function for growth of adeno-associated virus: effect of temperature-sensitive mutations in adenovirus early gene region $2, \mathrm{~J}$. Virol., 35: 65-75.

Olivio, P.D., Nelson, N.J. and Challberg, M.D. (1991) Herpes simplex virus replication: the UL9 gene encodes an origin binding protein, Proc. Natl. Acad. Sci. USA, 85: 5414-5418.

Paterson, T. and Everett, R. (1990) A prominent serine rich region in Vmw 175, the major transcriptional regulator protein of herpes simplex virus type 1 is not essential for viral growth in tissue culture. $J$. Gen. Virol. 71: 1775-1783.

Richardson, W.D. and Westphal, W.D. (1981) A cascade of adenovirus 
early functions is required for expression of adeno-associated vins, Cell, 27: 133-141.

Richardson, W.D. and Westphal, W.D. (1984) Requirement for either early region $1 \mathrm{~A}$ or early region $1 \mathrm{~B}$ adenovirus gene products in the helper effect for adeno-associated virus, J. Virol., 51: 404-410.

Roizman, B. (1990) Herpes viridae: a brief introduction. In B. Fields and D. Knipes (Eds.), Virology, Raven Press, New York, pp. 1787-1794.

Roizman, B. and Jenkins, F. (1985) Genetic engineering of novel genomes of large DNA viruses, Science, 229: 1208-1214.

Roizman, B. and Sears, A. (1990) Herpes simplex virus and their replication. In B. Fields and D. Knipes (Eds.), Raven Press, New York, pp. 1795-1842.

Rose, J.A., Maizel, J.K. et al. (1971) Structural proteins of adenovirus-associated viruses, J. Virol., 8: 766-770.

Samulski, R.J., Chang, L.-S. and Shenk, T. (1987) A recombinant plasmid from which an infectious adeno-associated virus genome can be excised in vitro and its use to study viral replication, J. Virol., 61: 3096-3101.

Samulski, R.J., Chang, L.-S. and Shenk, T. (1989) Helper-free stock of recombinant adeno-associated viruses: normal integration does not require viral gene expression, J. Virol., 63: 3822-3828.

Samulski, R.J., Zhu, X., Xiao, X., Brook, J.D., Housman, D.E., Epstein, N. and Hunter, L.A. (1991) Targeted integration of adeno-associated virus (AAV) into human chromosome 19, EMBO J., 10: 394l-4950.

Shenk, T. and Williams, J. (1984) Genetic analysis of adenovirus, Curr. Topics Microbiol. Immunol., 111: 1-39.

Shi, M., Arsenakis, M., Tiollais, P. and Roizman, B. (1984) Expression of hepatitis BS gene by a herpes simplex type 1 vectors carrying aand b-regulated gene chimeras. Proc. Natl. Acad. Sci. USA, 81, 5867-5870.

Simon, R.H., Engelhardt, J.F., Yang, Y., Zepeda, M., Weber-Pendleton, S., Grossman, M. and Wilson, J.M. (1993) Adenovirus-mediated transfer of the CFTR gene to lung of non-human primates: toxic study, Hum. Gene Ther., 4:771-788.

Spaete, R.R. and Frenkel, N. (1982) The herpes simplex virus amplicon: a new eucaryotic defective-virus cloning amplifying vector, Cell, 30: 295-304.

Spaete, R.R, and Frenkel, N. (1985) The herpes simples virus amplicon: analysis of cis-acting replication functions, Proc. Natl. Acad. Sci. USA, 82: 694-698.

Stow, N.D. (1985) Mutagenesis of a herpes simplex virus origin of DNA replication and its effect of viral interference, J. Gen. Virol., 66: $31-42$.

Stow, N.D. and McMonagle, E.C. (1982) Propagation of foreign DNA sequences linked to a herpes simplex vinus origin of replication. In Y. Gluzman (Ed.), Eucaryotic Viral Vectors, Cold Springs Harbor Laboratory Press, Cold Spring Harbor, NY, pp. 199-204.

Stow, N.D. and McMonagle, E.C. (1983) Characterization of the TRs/IRs origin of DNA replication of herpes simplex virus type 1, Virology, 130: 427-438.

Strauss, S.E., Ginsburg, H.S. and Rose, J.A. (1976) DNA-minus temperature-sensitive mutants of adenovirus type 5 help adenovirus-associated virus replication, J. Virol., 17: 140-148.

Strivastava, A., Lusby, E.W. and Berns, K.I. (1983) Nucleotide sequence and organization of the adeno-associated virus 2 genome, J. Virol., 45: 555-564.

Tratschin, J.D., Miller, I.L., Smith, M.G. and Carter, B.J. (1985) Adeno associated virus vectors for high frequency integration, expression and rescue of genes in mammalian cells, Mol. Cell Biol., 5: 3251-3260.

Tsao, J., Chapman, M.S. et al. (1991) The three-dimensional structure of canine parvovirus and its functional implications, Science, 25: 14561464.

Verhaagen, J., Hermens, W.T.J.M.C., Holtmaat, A.J.G.D., Oestreicher, A.B., Gispen, W.H. and Kaplitt, M.G. (1995) Viral vector-mediated gene transfer in the nervous system: application to the reconstruction of neural circuits in the injured mammalian brain. In M.G. Kaplitt and A.D. Loew (Eds.) Viral Vectors, Academic Press, San Diego, CA, pp. 119-132.

Vlazny, D.A. and Frenkel, N. (1981) Replication of herpes simplex virus DNA: localization of replication recognition signals within defective virus genomes, Proc. Natl. Acad. Sci. USA, 78: 742-746.

Vlazny, D.A., Kwong, A.D. and Frenkel, N. (1982) Site specific cleavage/packaging of herpes simplex virus DNA and the selective maturation of nucleocapsids containing full length viral DNA, Proc. Natl. Acad. Sci. USA, 79: 1423-1427.

Von Magnus, P. (1954) Incomplete forms of influenza virus, Adv. Vir. Res., 2: 59-78.

West, M.H.P., Trempe, J.P. et al. (1987) Gene expression in adeno-associated virus vectors: the effects of chimeric mRNA structure, helper virus and adenovinus VAI RNA, Virology, 160: 38-47.

Xu, H., Federoff, H., Maragos, J., Parada, L. and Kessler, J. (1994) Viral transduction of trk $\mathrm{A}$ into cultured nodose and spinal motor neurons convey NGF responsiveness, Dev. Biol., 163: 152-161.

Yin, J., Kaplitt, M.G. and Pfaff, D.W. (1995) In vivo promoter analysis in the adult central nervous system using viral vectors. In M.G. Kaplitt and A.D. Loew (Eds.), Viral Vectors, Academic Press, San Diego, CA, pp. 157-172.

Zabner, J., Peterson, D., Puga, A.P., Graham, S.M., Couture, L.A., Keyes, L.D., Lukason, M.J., St. George, J.A., Gregory, R.J., Smith, A.E. and Welsh, M.J. (1994) Safety and efficacy of repetitive adenovirus-medjated transfer of CFTR cDNA top airway epithelia of primates and cotton rats, Nature Genet., 6: 75-83.

Zhou, S.Z., Broxmeyer, H.E. et al. (1993) Adeno-associated virus 2 mediated gene transfer in murine hematopoietic progenitor cells. Exp. Hematol. 21: $928 \rightarrow 933$. 